\title{
What Cultural Theorists of Religion Have to Learn from Wittgenstein; Or, How to Read Geertz as a Practice Theorist
}

\author{
Jason A. Springs
}

Amid the debates over the meaning and usefulness of the word "culture" during the 1980s and 1990s, practice theory emerged as a framework for analysis and criticism in cultural anthropology. Although theorists have gradually begun to explore practice-oriented frameworks as promising vistas in cultural anthropology and the study of religion, these remain relatively recent developments that stand to be historically explicated and conceptually refined. This article assesses several ways that practice theory has been articulated by some of its chief expositors and critics, and places these developments in conversation with comparable accounts of "social practices" by recent pragmatist philosophers. My aim in generating such a conversation is to illuminate the ways that Ludwig Wittgenstein's later work provides important resources for cultural analysis that are already implicit in practice theory, yet either frequently overlooked or dismissed by practice theorists. I demonstrate how a Wittgensteinian understanding of practice theory coheres with, and illuminates, Clifford Geertz's account of meaning, thick description, and religious practices. Reading Geertz as a practice theorist, I argue, helps alleviate the apparent

Jason A. Springs, Joan B. Kroc Institute for International Peace Studies, University of Notre Dame, Notre Dame, IN 46556, USA. E-mail: jspring1@nd.edu. I presented a much earlier version of this paper to the Religion and Public Life Colloquium at Princeton University's Center for the Study of Religion. I am grateful to all who contributed to that discussion, for Martin Kavka's response to the paper, concerns raised by Larry Stratton, Josh Dubler, Heather White, and Atalia Omer, and for the instructive criticisms that I received from the JAAR referees for this article.

Journal of the American Academy of Religion, December 2008, Vol. 76, No. 4, pp. 934-969 doi:10.1093/jaarel/lfn087

(C) The Author 2008. Published by Oxford University Press, on behalf of the American Academy of Religion. All rights reserved. For permissions, please e-mail: journals.permissions@oxfordjournals.org 
opposition between assessing meaning and analyzing power in the study of religious practices and institutions, and unsettles dichotomous accounts of belief and intentional action.

INVOKING LUDWIG WITTGENSTEIN as a resource for cultural analysis may stir in some students of religion a slightly nauseating sense of déjà $v u$. Any account of Wittgenstein's usefulness for the study of religion and culture must address why this might be so, and why his work tends to be identified with a fairly marginal, if not outright controversial, approach to cultural analysis. In the first section of this essay, I address this controversy in order to sidestep the usual philosophical conundrums that follow it. In the second section, I demonstrate how a Wittgensteinian understanding of practice theory might serve as a resource for enriching and expanding practice theory frameworks. To highlight its relevance to theory and method in the study of religion, I propose a practice theory reading of Geertz's application of "thick description" to religious practices.

\section{EXPLAINING RELIGION: "IS UNDERSTANDING RELIGION COMPATIBLE WITH BELIEVING?"}

It is occasionally overlooked that the "culture wars" of the late 1980s and 1990s among cultural anthropologists were preceded by the "rationality debates" of the 1960s and 1970s. ${ }^{1}$ In these earlier debates, a host of sociologists, anthropologists, and philosophers turned their attention to the puzzles that emerged when anthropologists left their Victorian gentleman-scholar armchairs and actually entered into the worlds of fieldwork. The explanatory challenges that they encountered there raised questions about how truly "scientific" social scientific investigation of human life forms could be. Fieldwork raised a series of troubling questions. Should the field analyst assess the practices of some foreign tribe or culture against the notion of "universal rationality" (typically conceived as rules

\footnotetext{
${ }^{1}$ The term "culture wars" here refers to the debates among cultural anthropologists over the usefulness of the term "culture" in recent decades. Representative contributions include Fox and King (2002), Dirks (1998), Abu-Lughod (1991), Steedly (1996), Gupta and Ferguson (1992: 6-23), and Clifford and Marcus (1986). The first round of the so-called "rationality debates" included contributions from MacIntyre, Winch, Steven Lukes, Martin Hollis, Ernest Gellner (among others), which were collected in Rationality (Wilson 1970). A second volume devoted to these debates followed with additional contributions from Taylor, Ian Hacking, Robin Horton as well as reprises from Lukes, Hollis, Gellner, and were collected in Rationality and Relativism (Hollis and Lukes, 1982). Geertz added his voice to the fray in his essay "Anti Anti-Relativism" (1984).
} 
of logical coherence, non-contradiction, and publicly repeatable testability)? And if there were no such universal standards available, was any culture or way of life potentially valid and as acceptable as any other when examined from within its own frame of reference? Furthermore, could the anthropologist ever be "strictly local" vis-à-vis his subject matter? That is, could he make judgments about his research subjects without imposing his own parochial background and biases upon them? The debates about "rationality" inspired by these questions took as a case study in the Evans-Pritchard's analysis of the witchcraft practices of the Azande tribe of southern Sudan-a story now the stuff of legend (or a happily forgotten vestige of myth) among scholars of religion.

After immersing himself in the Azande worldview and witchcraft customs as sympathetically as possible between 1926 and 1931, EvansPritchard delivered his verdict that Azande oracular practices were patently irrational. They refused even the barest ground rules of rationality (Evans-Pritchard 1937; Winch 1970b: 78-111; Pals 1996, chap 6). Several of Evans-Pritchard's readers responded that his declaration of irrationality was itself quite peculiar. Some of these critics based their objections on Ludwig Wittgenstein's claim that "forms of life" (of which the Azande tribe was believed to present an instance) are embodied in their own bounded language games. Such language games provide conceptual frameworks "within which we ask questions, carry out investigations, and make judgments" (Malcolm 1977: 94-95). ${ }^{2}$ Hence, for Evans-Pritchard to assess the Azande practices by standards extraneous to that way of life was like criticizing basketball players for not properly observing the rules of baseball. As Norman Malcolm put the point, "Religion is a form of life; it is language embedded in action - what Wittgenstein calls a 'language game.' Science is another. Neither stands in need of justification, the one no more than the other" (Malcolm 1977: 156). ${ }^{3}$ On this account, understanding, investigating,

\footnotetext{
${ }^{2}$ Malcolm's uses of these terms from Wittgenstein date back to his initial explication of Wittgenstein's Philosophical Investigations (Malcolm 1954). "Forms of life, embodied in languagegames, teach us what justification is. As philosophers we must not attempt to justify the forms of life, to give reasons for them-to argue, for example, that we pity the injured man because we believe, assume, presuppose, or know that in addition to the groans and writing, there is pain. The fact is, we pity him. 'What has to be accepted, the given, is-so one could say-forms of life' $(P I, 226)$. What we should say is: 'This language-game is played' (654). From this major theme of Wittgenstein's thought, one passes easily to another major theme-that 'Philosophy simply puts everything before us, and neither explains nor deduces anything' (126). 'It leaves everything as it is' (124)" (Malcolm 1954: 550).

${ }^{3}$ In his treatment of these ideas, Malcolm drew upon a prior application of Wittgenstein to social analysis by Winch (1958). There Winch had written, "[C]riteria of logic are not a direct gift of God, but arise out of, and are only intelligible in the context of, ways of living or modes of
} 
and evaluating a form of life ought to conform to the standards of justification and rationality particular to that form of life. Otherwise, analysts reduce the object of investigation to something other than what it is. When that happens, the analyst "outsider" usually ends up peering down a well at a likeness that reflects his own methodological preferences and cultural background.

Several arguments in the rationality debates were advertised as Wittgensteinian because they were inspired, at least in part, by Wittgenstein's criticisms of Sir James Frazer's The Golden Bough (Wittgenstein 1993: 115-155). ${ }^{4}$ Frazer had set out to account for the magic practices of the primitive peoples he studied in terms of a purportedly universal (but, in fact, quite distinctively instrumental) form of rationality. In doing so, he had, in effect, reduced these particular magic practices to primitive science. The magicians in question were engaged in archaic efforts to explain, predict, and control their environments. Frazer's explanation roused the ire of Wittgenstein. "What a narrow spiritual life on Frazer's part!" he wrote. "As a result: how impossible it was for him to conceive of a life different from that of the England of his time! Frazer cannot imagine a priest who is not basically a present-day English parson with the same stupidity and dullness" (Wittgenstein 1993: 125). Some of Wittgenstein's complaints against Frazer appeared to challenge any account that did not privilege the religious practitioner's point of view. Thus, when Frazer imposed a scientific interpretation upon indigenous magic practices, Wittgenstein found the resulting attempts at explanation "much cruder than the meaning of these practices themselves" (131). In fact, Wittgenstein's

social life as such. For instance, science is one such mode and religion is another; and each has criteria of intelligibility peculiar to itself. So within science or religion actions can be logical or illogical .... But we cannot sensibly say that either the practice of science itself or that of religion is either illogical or logical; both are non-logical" (100-101).

${ }^{4}$ It should be noted that the terms "form of life" and "language game" never directly appear in "Remarks On Frazer's Golden Bough." Nonetheless, it is clear that several contributors to the rationality debates viewed these notions from Wittgenstein's Philosophical Investigations and on Certainty as consistent with-even illuminating-his criticisms of Frazer's attempt to render explanation across vast cultural and historical differences (Winch had acquired a manuscript of the remarks from Rush Rhees long before their initial publication) (Winch 1970b: $103 \mathrm{n} 1$ ). Other explicit uses of Wittgenstein's treatment of Frazer in the context of the rationality debates include Taylor (1982: 87-105) and Lukes (1982: 261-305). My concern with Wittgenstein's assessment of Frazer in the present section is with the uses made of it in the rationality debates, particularly, how it was employed to corroborate so-called "fideist" readings of Wittgenstein. The accuracy of these uses to the letter of that text is a different question. Examples of more recent work on what Wittgenstein really intended in his "Remarks on Frazer's Golden Bough" see Cioffi (1998), Clack (2001), and Phillips (2001: 146-182). 
remarks seemed to prohibit any attempt at explanation whatsoever. He wrote:

The very idea of wanting to explain a practice-for example, the killing of the priest-king-seems wrong to me. All that Frazer does is to make them plausible to people who think as he does. It is very remarkable that in the final analysis all these practices are presented as, so to speak, pieces of stupidity. (1993: 119)

Wittgenstein appeared to say that grasping the meaning of these practices was altogether different from explaining them. The former limited itself to understanding those practices on their own terms, and in their particular contexts. ${ }^{5}$

Wittgenstein's criticisms of Frazer served as a central point of contention in the critical exchange between Alasdair MacIntyre and Peter Winch in the opening rounds of the "rationality debates." There MacIntyre set out to determine whether or not understanding religion was compatible with believing in it (MacIntyre 1970a: 62-77). Clearly, MacIntyre reasoned, in attempting to understand some group's religious beliefs from across a great cultural divide, an analyst ought not impose her own cultural frame of reference upon her object of investigation unreflectively, which Frazer had done. That said, MacIntyre continued, in rendering the social and epistemic standards of some alien context intelligible, it is impossible for the analyst not to invoke the established standards of her own social context. Moreover, it should be possible on that basis to recognize that concepts believed to be coherent and intelligible in the context under investigation are, in fact, cognitively incoherent, practically self-defeating, and ultimately non-sensical. The capacity to render such an explanatory account would attest to the rational superiority of the latter context.

5 In his now classic treatment of religious experience, Wayne Proudfoot demonstrated how D. Z. Phillips marshaled the foregoing passages from Wittgenstein's "Remarks" in support of his case against all forms of explanatory reduction of religious practices. Specifically, Phillips took Wittgenstein's criticisms of Frazer's scientific explanation to exemplify a general, anti-reductionist approach to religious phenomena-"that religious beliefs are irreducible in the sense that they cannot be explained in nonreligious terms." Responding to passages from Phillips's Religion without Explanation (1976: 150), Proudfoot pointed out that Phillips's account resulted in "protecting" religious practices from all external assessment and reductive explanation (Proudfoot 1985: 208-209). Phillips nuanced this reading of Wittgenstein in his later writings. "It appears ... that Wittgenstein is not opposed to all explanations of practices, which would be an absurdity in itself," Phillips wrote, citing another passage in Wittgenstein's remarks (1993: 139). "Yet he does seem to think that there is something profoundly inadequate in Frazer's explanations of rituals [as erroneous scientific beliefs]" (Phillips 2001: 177-182). The extent to which Phillips's later work actually succeeds in extricating his position from the anti-reductionist commitments is a question that I have not space to address in the present essay. 
A perfect example of such cross-context explanation, MacIntyre thought, was the process of secularization that Christian thought and practice has undergone in modern, western societies since the seventeenth century. "[W]hy do the same intellectual difficulties at one time appear as difficulties but no more, an incentive to enquiry but not a ground for disbelief, while at another time they appear as a final and sufficient ground for skepticism and the abandonment of Christianity" (73)? As construed by MacIntyre, the secularization of western society led up a conceptual promontory from which philosophers and critics of religion, anthropologists, and sociologists could provide a full-blown explanatory account of the follies of religious belief that were characteristic of previous epochs and primitive foreign cultures. Such an account would explain the shifts that had occurred in the respective social and practical context along with changes in its epistemic procedures and values, all of which contributed (as a matter of historical fact) to the increasing incredibility of religious belief. For Christian thinkers of the Middle Ages, for instance, MacIntyre wrote:

[T]he apparent incoherence of Christian concepts was taken to be tolerable (and treated as apparent and not real) because the concepts were part of a set of concepts which were indispensable to the forms of description used in social and intellectual life. It is the secularization of our forms of description, constituting part of the secularization of our life, that has left the contradiction high and dry. (74)

In light of these developments, MacIntyre believed he could explain why so many twentieth-century Christian thinkers had no choice but to retreat into conceptions of "the absurd," "paradox," and "mystery." These concepts provided bulwarks against naturalist explanations, rendered Christianity "logically invulnerable" and, in practice, immune to empirical falsifiability. As MacIntyre saw it, modern Christianity evinced the same invulnerability to naturalist explanation as Winch's exemption of Azande witchcraft practices from external criticism and reductive analysis (1970a: 76-77).

MacIntyre's ascent to the summit of western secularization for an explanatory vantage-point appeared to Winch to be more like a mad dash over the edge of a steep precipice. Below awaited the rocks of interpretive hubris, ethnocentricism, and cultural hegemony. Azande "believing" repelled "understanding" only insofar as the latter term was code for instrumental and scientific forms of explanation that were motivated by distinctively modern and western cultural values. With Wittgensteinian tools in hand, Winch expanded his earlier claims that "intelligibility takes 
many forms," and that that there is no "norm for intelligibility in general" (Winch 1958: 102). ${ }^{6}$ On this reading, while Wittgenstein succeeded in moving concepts like belief and meaning from the hidden interiority of "mind" and "consciousness" into the space of public practices and situated bodies, he nonetheless sequestered those practices and bodies from explanatory analysis and external criticism. "Language games" would have to be understood on "insiders" terms. They were not reducible to terms of some allegedly more basic domain, nor even finally translatable into comparable idioms without a significant loss of meaning. Thus, legitimate criticism-and even genuine understandingwere possible only in the terms set by the language game or form of life in question. "As regards 'explanation'," the Wittgensteinian camp in the "rationality debates" glossed the objection, "the new view is that there are many different concepts of 'explanation', each one operating in a particular language-game. But a language-game itself rests on no grounds that explain or justify it, and show it to be reasonable or unreasonable. It can only be observed and described" (Malcolm 1995: 78). The methodological implications of this account were clear: analysts should not try to determine whether one form of life or language game was better than another. Forms of life are just different, and questions of "truth" are relative to each culture's domain (Nielsen 1967: 191-209; Phillips 1971: 121-142, 1976). The true task of philosophy-and, by analogy, of cultural and social analysis-is not to explain or deduce anything, only to describe it. Such an investigation "puts everything before us" yet "leaves everything as it is" (Phillips 2001: 167; Wittgenstein 2002: sec 126, 124).

As the rationality debates smoldered on into the 1980s, various readers of Wittgenstein became increasingly dissatisfied with both sides. Especially, dissatisfying was the increasingly close association of Wittgenstein's highly idiosyncratic, at times baffling, and seemingly endlessly generative later work with a particular philosophical camp, and an apparently intractable debate. These readers pointed out that charges and counter-charges of "Wittgensteinian fideism" largely missed the spirit of his work. Wittgenstein had not sought to construct a new philosophical framework or a comprehensive approach to analysis, and certainly not to initiate a new philosophical sect. Neither would he have been pleased to opt for either horn of the so-called "insider/ outsider dilemma." $\mathrm{He}$ sought rather to diagnose and inoculate the

\footnotetext{
${ }^{6}$ Winch's opening essay in Rationality (Wilson 1970), entitled "The Idea of a Social Science" (Winch 1970a), distilled what he would later identify as "the central core of the argument" from his earlier book of the same title (Winch 1958).

${ }^{7}$ For a sense of how this debate has unfolded in the study of religion, see McCutcheon (1999).
} 
desires and dispositions that make conundrums like the insider/outsider debate and standoffs between protective strategies and reductionism appear to be analytically productive in the first place. He sought to exchange theoretical and philosophical obsessiveness for the particular, the textured, and the detailed. The motivating insight was a counterpoint to the claim that languages and cultures form discrete and clearly defined systems shared and applied by practitioners. These are too fluid and flexible; there are no hard and fast peripheries of cultures to demarcate, no bounded wholes of language that are inherently relation-less. The methodological upshot was that, whether with research subjects, several millennia distant or interlocutors just around the corner, sound and charitable understanding is not optional. ${ }^{8}$ In fact, it is prerequisite for identifying differences, making assessments, and administering criticism. Differences that allegedly cut all the way down forego any shared subject matter over which to differ. ${ }^{9}$ Hence, the more purely absurd, thoroughly unintelligible or simply reprehensible the subject matter appears to the investigator, the more likely he has made himself a savage amidst the civilized, eavesdropping upon the conversations of strangers only to "put a false interpretation on them, and then draw the queerest conclusions from it" (Wittgenstein 2002: sec. 194).

This reading of Wittgenstein was not yet another call to somehow empathetically and imaginatively "step into the shoes" of one's research subjects. Nor was it a simple reversion to a default position of classically liberal humanism that all human beings participate in a foundationally common "human condition" which ought to orient the investigator's engagement with his subject matter (Smith 1959: 42; McCutcheon 2006: 720-726). Quite the contrary, on the one hand, Wittgenstein proposed a sensibility of sound understanding predicated on the insight that the very possibility of recognizing radical and enduring differences-and assessing

\footnotetext{
8 The key articulation of this point is Donald Davidson (1973) "On the Very Idea of a Conceptual Scheme"; for a meticulous exegetical account of how Davidson's argument coheres with (and to some degree presupposes) central ideas in Wittgenstein's later writings, see Jim Hopkins (1998) "Wittgenstein, Davidson, and Radical Interpretation," and Richard Rorty (1992) "Wittgenstein, Heidegger and the Reification of Language"; the crucial anthropological expansion on these connections can be found in Bowlin and Stromberg (1997), "Representation and Reality in the Study of Culture"; for an account of precisely how Davidson's "principle of charity" is unavoidable, and how it might fit with the Continental European tradition of hermeneutics, see David Hoy (1996) "Post-Cartesian Interpretation;" Bjorn Ramberg explicates the inescapability of Davidson's "principle of charity" in direct response to Steven Lukes' contribution to the second volume of the rationality debates, "Relativism in its Place" (Ramberg 1991: 74-81).

9 Though perhaps unfamiliar to many scholars of religion, this methodological insight was thoroughly explicated in the sub-field of religious ethics throughout the 1980s in an extended exchange between MacIntyre and Stout (MacIntyre 1986; Fowl 1991; Stout 2001).
} 
meaningful disagreements-presupposes the actuality of more broadly encompassing similarities, and possibilities of translatability and communication. On the other hand, however, coming to "find one's feet" among strangers in some alien country and unfamiliar circumstance is far different, and far more difficult, than imagining a foreigner's feet as one's own. It does not preclude encountering them as enigmatic to one's observations, perhaps in spite of having learned their languages, investigated their traditions, and studied their texts (Wittgenstein 2002: 223). In other words, the whole of understanding is far more nebulous than the sum of its parts. Understanding tends to be ad hoc, textured and moment-to-moment, accomplished more in a sensus of daily details such as "grasping a proverb, catching an allusion, seeing a joke... than achieving communion" (Geertz 1983: 241). ${ }^{10}$

So understood, the sensibility portrayed by Wittgenstein in his later work relocated cultural investigation and humanistic inquiry from the sphere of strict application of methodology to the realm of craft and art (techne). In applying a methodology one would, for instance, feed data into one end of a prefabricated general theory and then chronicle and construe the results. Perhaps it would group cases under logical principles of rationality. Mastery of an art or craft, in contrast, requires phronesis-embodied, practical wisdom that begins by discerning and demonstrating connections, yet without collapsing the (occasionally radical) differences. It makes specific identifications, draws inferences, and renders assessments on a case-by-case basis, yet without losing a sense of broader scope. At the same time, quieting the theoretical fixations and anxieties symptomatic of modern forms of philosophical, knee-jerk skepticism need not prohibit explanatory forms of investigation when they are appropriate. Explanation has its uses, and there is no subject matter that intrinsically eludes it. "Every miracle can be [naturally] explained-after the event," Franz Rosenzweig illuminated the point. "Not because the miracle is not a miracle, but because explanation is explanation" (Rozensweig 1998: 290).

What this Wittgensteinian sensibility does proscribe is fetishizing scientific explanation-setting it up as the way theorizing must be done, or a final court of appeal. Wittgenstein, in contrast, sought to sidestep philosophical skepticism and its progeny, namely, the Cartesian fixation with rational certainty and the positivist's yearning for empiri-

\footnotetext{
${ }^{10}$ Richard Bernstein provides a helpful account of the differences between Winch's uses of Wittgenstein to address Evans-Pritchard, and Geertz's take on the Wittgenstein sensibility I describe above (Bernstein 1983: 93-108).
} 
cal verifiability. ${ }^{11}$ He portrayed a practical sensibility that first aims at richly textured and fine-grained encounters and comparisons, thereby facilitating judgments of all sorts: critical, explanatory, comparative, contrastive, thickly descriptive, and redescriptive. This sensibility is practical in the sense that determining which form of judgment was most suitable depends upon the particular task at hand, and the interests and purposes in question. It is fallibilist because it refuses to consider any single form of judgment exhaustive of the investigative possibilities, and considers any particular judgment revisable in light of further information and experience and the inevitable partiality of human ways of knowing. Finally, this sensibility reflects special attention to practice because it was motivated by the belief that philosophical justification and explanation of what people believe and do, and scientific investigation of what there is, are derivative of daily life and ordinary practices.

The debates over so-called "Wittgensteinian fideism" wore thin long ago. In the judgment of many who followed closest, they have been effectively resolved for some time. ${ }^{13}$ They remain instructive for those who conduct humanistic inquiry into unfamiliar practices, habits and beliefs, foreign institutions, and antiquated texts and languages. Unfortunately, Wittgenstein's marginal presence as a resource in cultural theory and the study of religion may be due to residual specters associated with these debates-specters of relativism and fideism, charges and counter-charges of reductionism or protectionism. ${ }^{14}$ In the

\footnotetext{
${ }^{11}$ For an exceptional account of these relations, see Toulmin (1990).

${ }^{12}$ For a succinct overview of the ways that Wittgenstein positively influenced practice-orientedand pragmatic-philosophers in the twentieth century (yet which avoids the mis-step of pigeonholing Wittgenstein as a pragmatist philosopher), see Bernstein's "The Pragmatic Century" (Davaney and Frisina 2006: 1-14).

${ }^{13}$ Some of the best work in the philosophy of religion and cultural theory during the 1980s was devoted to mediating this debate in ways that rendered innocuous charges of "fideism," "incommensurable cultural enclaves" or conceptual relativism. A sampling of the most important examples would have to include Stanley Tambiah's 1984 Henry Lewis Morgan Lectures, published as (1989) Magic, Science, and the Scope of Rationality; Joseph Incandela (1985) "The Appropriation of Wittgenstein's Work By Philosophers of Religion: Towards a Re-Evaluation and an End"; Stout (1981) The Flight from Authority, esp. chap 8; Bernstein (1983) Beyond Objectivism and Relativism, esp. pp. 25-34, 93-108; William Placher (1989) Unapologetic Theology, esp. chaps 2-4; Hilary Putnam's 1990-91 Gifford Lectures published as (1992) Renewing Philosophy, esp. chaps 7-8. Three treatments of Wittgenstein's work particularly helpful in side-stepping charges of noncognitivism, regulism, and relativism are Sabina Lovibond (1983) Realism and Imagination in Ethics; James C. Edwards (1983) Ethics without Philosophy: Wittgenstein and the Moral Life and (1990) The Authority of Language. Many of the ideas seminal to this current of thought about Wittgenstein were articulated much earlier in Sellars (1954).

${ }^{14}$ The recent volume containing the extensive exchange between Nielsen and Phillips (2005) arguably does more to perpetuate this perception than to alleviate it (cf. Harvey, 2007). Proudfoot
} 
remainder of this paper, I approach Wittgenstein's influence from a different angle. I aim to demonstrate that several of his most fruitful insights for cultural analysis are already implicit (albeit tacitly) in the central claims of the types of practice theory that emerged among cultural anthropologists in the 1980s and 1990s. Making those insights explicit will draw Wittgenstein openly into the conversation about the study of religion and culture, and in more productive ways. I hope to show that an encounter with Wittgenstein can critically enrich practice theory by resolving an alleged opposition between so-called power analysis and practice theory.

As we will see below, practice theory is often identified as indifferent to the task of critically analyzing the practices it investigates. Some charge that it lacks altogether the resources needed to administer sustained, systemic analysis of the power dynamics that organize the practices that it observes and describes. Similarly, Wittgenstein remains associated with the legacy of "philosophical quietism"- the claim that philosophy of a Wittgensteinian type "simply puts everything before us, and neither explains nor deduces anything" and finally "leaves everything as it is" (Malcolm 1954: 550). ${ }^{15}$ On this reading, the aims of analysis are to observe, understand, and contemplate, and then perhaps describe meanings. Explanation and criticism are to be avoided, as are "constructive or doctrinal ambitions" (McDowell 1996: 93). I aim to demonstrate that a Wittgensteinian understanding of practice theory is not relegated to "theoretical quietism" of this sort. In fact, it does not merely accommodate power analysis but actually contains resources for executing such analysis.

\section{PRACTICE THEORY IN CULTURAL ANALYSIS SINCE THE $1960 \mathrm{~S}$}

As Sherry Ortner describes it, practice does not propose a "theory" in the traditional sense. In other words, it does not forward a set of systematically related, law-like generalizations that claim to organize bits of data in order to predict, control, or comprehensively explain the designated phenomena (Ortner 1983). Practice theory refers to an approach

(1985: 209-215) read Phillips's rejection of explanatory reduction as intrinsic to Wittgenstein's thinking; Dan Stiver's survey of the uses of Wittgenstein's later thinking by philosophers of religion delivers an ambivalent verdict at best about its prospects for overcoming these difficulties. See Stiver (1996) The Philosophy of Religious Language, esp. chap. 4 and pp. 139-153.

${ }^{15}$ Sections in Wittgenstein's Philosophical Investigations frequently invoked in support of a "theoretical quietist" or "deflationary" reading of his work include 109, 116, 124, 126, 127, and 128 (Soames 2002: 27-31). 
to understanding and description that lacks a formal unity, and avoids a single over-arching explanatory account. It is better described as an argument that attends primarily to the creative and transformative potential of "what people do" by virtue of the antecedently instituted normative constraints that make their "doings" possible in the first place. As Ortner puts it, "Within a practice framework there is an insistence, as in earlier structural-determinist models, that human action is constrained by the given social and cultural order (often condensed in the term 'structure'); but there is also an insistence that human action makes 'structure'-reproduces or transforms it, or both" (Ortner 1996: 2). Ortner considers this latter insight to be the "fundamental assumption of practice theory" (Ortner 2006: 29).

The emergence and development of practice theory has been a twowave phenomenon: the initial development of its basic ideas, and later, application of those ideas for the purposes of "engaged scholarship" such as feminist and subaltern studies. Ortner suggests that the increased interest in practice among British and American anthropologists began to coalesce at roughly the time that the English translation of Pierre Bourdieu's Outline of a Theory of Practice circulated in 1978. This was accompanied by multiple efforts to integrate Marxist and Weberian analytical frameworks. As she tells the story, a handful of analysts began to recognize that the tensions in Weber's work between the actions of particular agents and concerns about "ethos" and "consciousness" could fit together complementarily with Marx's account of praxis. Without altogether displacing the prevailing talk of "systems" or "structures," these thinkers reoriented such terms around human action, construed broadly as anything people do. They refused to posit notions of "system" and "structure" as given or static. They sought, instead, to investigate where and why such "systems" occurred, how they were "produced and reproduced" in order to re-describe and critically interrogate them. ${ }^{16}$

"First wave" practice theory was only tangentially concerned with issues of power and resistance. "Second wave" practice frameworks are marked by a range of political interests (Ortner 1996: 3). The constraints that constitute practices are recognized as in-eliminably inscribed with hegemony, symbolic domination, and power differentials. Ortner claims that identifying, describing, and interrogating these

\footnotetext{
${ }^{16}$ Early instances of this framework include Anthony Giddens' Central Problems in Social Theory (1979), Marshall Sahlins' Historical Metaphors and Mythical Realities (1981), and Michel de Certeau's The Practice of Everyday Life (English trans., 1984). Ortner drops Certeau entirely from her recently updated account of these developments (Ortner 2006: chap 1).
} 
practices, structures, and systems serve the primary purposes of critique and resistance. She writes:

Whether it is a matter of focusing directly on interaction-even struggle-between asymmetrically related actors (whatever they are doing) in terms of roles and statuses derived from asymmetrical relations in which they participate, the approach tends to highlight social asymmetry as the most important dimension of both action and structure. (Dirks et al. 1994: 393; cf. Ortner 1996: 139-172)

In other words, second-wave practice theorists ask: "Why these practices?" and "From what material conditions and social processes did they arise?" and "What dynamics hold them in place?" More importantly, "What are the tacit presuppositions and unrecognized implications of such practices?"

Ortner has worked to develop practice theory in the direction of "engaged anthropology" in much of her own work. She has demonstrated its relevance for broader areas of social thought in virtue of its ability to interrogate and transform forms of power and domination (Ortner 1999: 136-139). And yet, Ortner may inadvertently overlook the capacities of certain versions of practice theory to address issues of power by compartmentalizing her account into dual categories of "first" vs. "second wave," "resistance" vs. "non-resistance," and limiting her account of practice theory's emergence to the influences of Weber, Marx, and Bourdieu. The resources for "theorizing practice" may be more fluid and internally complex than such categorization permits.

In my judgment, carving up the conceptual terrain as she does overlooks opportunities to establish broader connections with other areas of social thought. Such broader connections might enrich the framework, and bring thinkers into conversation across disciplinary boundaries.

For instance, Ortner excludes Geertz from her account of practice theory. Two obstacles allegedly prohibit his inclusion. First, because Geertz frames his ethnographic approach primarily in terms of meaning, he remains caught in what Ortner calls "the textual turn." Secondly, he either refuses to take up questions of power or treats such questions too superficially when he does. Geertz overlooks how construing "cultures as texts" is itself an act of power that stands to be interrogated (Pecora 1989: 243-276; Dirks et al. 1994: 22, 36-39). Ortner considers this deficiency in Geertz's work indicative of "meaningoriented" frameworks generally. She concludes that "The Foucault/Said shift, along with all the other shifts in cultural theorizing toward the power of power effectively knocks out, or drastically narrows, questions 
of meaning and 'culture' in the Geertzian sense" (Ortner 1999: 138-139). In other words, meaning and power appear to stand in opposition to one another. ${ }^{17}$ But is it necessary to oppose the "the textual turn" and the "Foucault/Said shift" to power analysis in this way? Might this dualistic opposition be another by-product of the particular way that Ortner has marked out the terrain?

In the following section, I propose to re-read Geertz as a Wittgenstein-inspired practice theorist. Tracing out the Wittgensteinian elements implicit in Geertz' work serves three purposes. First, it should expand and enrich Ortner's account of the history and character of practice theory. Second, approaching Geertz with an eye to the social and practical background of his account provides an example of what a Wittgensteinian understanding of practice theory might look like. Third, the ensuing understanding of thick description, "culture" and "meaning" should disabuse Geertz of several of the more dogged and redundant criticisms aimed at his work. In particular, it challenges the classification of his work as an instance of "semiotics" and demonstrates its more fitting location in pragmatics. ${ }^{18}$ Re-reading Geertz as a practice theorist should enable us to overcome the conventional dismissal of his project on grounds that it essentializes notions of "systems" and "symbols." If this reading is successful, then "thick description" may not, in fact, stand so distant from "engaged" or "resistance" modes of cultural analysis after all.

\section{PRACTICE THEORY AS A KIND OF WRITING: RE-READING GEERTZ}

Geertz drew on a range of theoretical resources in order to articulate his approach. Which of these resources are taken to be most influential in his work depends largely upon which dimensions of Geertz's project one takes to have normative sway. Taking "meaning" or "symbol" as the primary points of entrée into his work foregrounds influences like Kenneth Burke, Northup Frye, Susan Langer, and Paul Ricoeur (Geertz 1973: 36). When the notion of "systems" is positioned as the orienting concept, Talcott Parsons and "pure systems" theory becomes Geertz's

\footnotetext{
${ }^{17}$ Having so marked out the field of play, Ortner then sets out to mediate this opposition in her own work (Ortner, 1995: 173-93, 1999: 136-159, 2006).

18 Technically speaking, semantics and pragmatics are sub-divisions of semiotics, which is broadly construed as the study of signs. Semantics studies the relations between signs and the objects to which they apply, whereas pragmatics studies the relation between users and uses of systems or structures of signs (e.g., appropriate moves in conversation).
} 
primary influence (Asad 1993: 32). Wittgenstein's influence on Geertz is often overlooked. Indeed, Wittgenstein's explicit presence in The Interpretation of Cultures is highly disproportionate to the weight of his influence there. And yet, Geertz invokes multiple facets of Wittgenstein's later work: the notion of "family resemblances," meaning as both public and a matter of use (or meaning as a social practice), "language games" as a model for cultural practices, and a non-hermetic understanding of "forms of life." It was not until long after his work of the 1960s that Geertz articulated the full depth of his indebtedness to Wittgenstein, writing:

[W]ittgenstein's attack upon the idea of a private language, which
brought thought out of its grotto in the head into the public square
where one could look at it, his notion of a language game, which
provided a new way of looking at it once it arrived there-as a set of
practices-and his proposal of 'forms of life' as (to quote one commen-
tator) the 'complex of natural and cultural circumstances which are
presupposed in ... any particular understanding of the world', seem
almost custom designed to enable the sort of anthropological study
I, and others of my ilk, do. (Geertz 2000: xi-xii; cf. Micheelsen
2002: 4-6)

Geertz complements his appropriation of Wittgenstein with a second influence-one that he much more explicitly acknowledged-Max Weber. Geertz identifies Weber as the source of his seminal claim that humans are "meaning making animals caught up in webs of significance that they themselves have spun" (1973: 5). Of course, a terse appeal of "webs of significance" leaves much to be desired in the way of an explanation of the nature of "meaning." And precisely on this point Geertz incurs criticism from anthropological interlocutors, not merely as an oversight but as a terminal deficiency.

"What, exactly, are meanings?" and "Where do they come from?" Christopher Herbert interrogates Geertz. "How exactly do they become inscribed upon material object or social practices?" Herbert complains that Geertz does not-perhaps because he cannot-provide a straightforward answer. Herbert thus infers from Geertz's characterization of "meaning" as "elusive and ill-defined pseudoentity" that it is, therefore, "a metaphysical phantom" (Geertz 1973: 29). And this creates tremendous dissonance for Herbert. How can ethnographic studies pursue meanings when these turn out to be "intrinsically incomplete' and produce 'no conclusions to be reported' (IC 29)," Herbert writes. "[Geertz] goes so far as to assert that 'the more deeply [ethnography] 
goes the less complete it is' (IC 29)." One need not take this last declaration as a considered judgment to see how vividly it reflects the crisis-laden character of the mature culture doctrine" (Herbert 1991: 26). If talk of "meanings" does not refer to something solid and traceable, then persistent use of this term to refer to the goal of ethnographic analysis evinces a serious crisis in the field (Roseberry 1989: 26). Indeed, Geertz's frequently quoted appeal to Weber gives rise to pigeon-holing his ethnographic approach as "meaning centered." This misunderstanding might be resolved by re-framing his position as most basically concerned with social practices rather than semiotics or semantics.

One of Geertz's primary innovations in The Interpretation of Cultures was to talk about "culture" as a public, social context and set of relationships in and through which people interact meaningfully with one another. So understood, the purpose of ethnographic analysis is to make sense of what the members of a given society understand themselves and one another to be doing in virtue of their interactive participation in the symbol or meaning "systems" that fill out that context. "When Weber says that man is an animal suspended in webs of significance he himself has spun," Geertz famously wrote, "I take culture to be those webs, and the analysis of it to be therefore not an experimental science in search of law but an interpretive one in search of meaning" (1973: 5). What does it mean to be caught up in webs of significance? And how does this reflect social practice? A practice theory reading of Geertz might look something like the following.

Geertz glosses Weber's "webs of significance" as "socially established structures." To call these webs "piled-up structures of inferences and implications" that constitute "a stratified hierarchy of meaningful structures" is to say that they are socially constituted, inferentially articulated networks of referential practices and equipment (praxis and pragmata) to which Geertz applies the term "cultural systems" (1973: 7). Becoming "caught up in" these refers to the various processes by which one is socialized or acculturated into the practices and shared dispositions that constitute those "structures." Someone need not be born into a cultural situation in order to be "caught up in the webs of significance" that characterize it. One might become an adept participant as a trained translator whose skills come to approximate the native speaker's, or a convert from a different set of practices, or however one might be said to "find one's feet" among "people in a strange country with entirely strange traditions," an insight he borrows from Wittgenstein (1973: 13). Insofar as one is capable of "finding one's feet" at all, one initially finds oneself "there"-suspended within a context that is filled out by 
inter-related sets of practices already up and running. On this view, one is not a discrete "self" prior to being "suspended" there. Rather, one's "self" is constituted through gradual acculturation into the social and practical webs of meaning that fill out the context in question. Acculturation into social practices is prerequisite for thought as well as experience. This is another claim that Geertz anchors in a Wittgensteinian insight:

[H] uman experience-the actual living through of events-is not mere sentience, but, from the most immediate perception to the most mediated judgment, significant sentience-sentience interpreted, sentience grasped. For human beings, with the possible exception of neonates, who except for their physical structure are human only in posse anyway, all experience is construed experience, and the symbolic forms in terms of which it is construed thus determine-in connection with a wide variety of other factors ranging from the cellular geometry of the retina to the endogenous stages of psychological maturation-its intrinsic texture. To abandon hope of finding the 'logic' of cultural organization in some Pythagorean "realm of meaning" is not to abandon the hope of finding it at all. It is to turn our attention toward that which gives symbols their life: their use. (1973: 405)

Read in this way, Geertz exchanges the picture of "... each person coming into a cultureless world and spinning such a world around him out of the substance of his inner self, as a spider spins his web out of his abdomen" for one in which "for any given individual certain acts, objects, tales, customs, and so on are already considered by the members of his society... to mediate a valid worldview by the time he is born into it" (1971: 99). Thus, "webs of meaning" are socially instituted-"collectively created patterns of meaning the individual uses to give form to experience and point to actions"-spun in the course of human practices in which particular human beings finds themselves caught up (1971: 95-96, 1973: 89).

Highlighting the ways that Geertz's use of the word "meaning" indicates a social, practical, and public orientation re-situates his account within a framework of social practice. So positioning it side-steps charges that his position implies that "action is meaningful because actors realize their acts to be so, and therefore recognize fully the significance of their actions" (Orville 1999). In fact, exhaustive recognition of significance would be impossible on a practice reading of Geertz's account, even from the first person perspective. There are any number of possible interpretations and re-descriptions available. "Whatever the devil it is that these people think they're up to," even the "native's point 
of view" does not exhaust possible significances nor declare by fiat "what's really going on." No hermeneutical advantage inheres in "insider status" by default, just as none inheres in the analyst's (whether she be "insider" or "outsider" or some mixture of the two). Of course, neither does this mean that any account is just as good any other. It acknowledges that everyone's claims are interpretive, open to examination, and accountable both to the norms of the inquiry at hand and to the practical context under examination.

It is largely a truism by now that cultural theorists constantly risk taking up an object of analysis that seems tailor-made for her theoretical framework precisely because they remain unreflective about the extent to which that framework informs and influences the object under investigation. And along these lines, the charge is sure to come that the "the textual turn" reduces the object of analysis to a projection of the analytical framework (Asad 1993: 29). However, this concern ascribes to Geertz a more essentializing objective than he takes up. Thick description does not set out to exhaustively explain-to get at some essential meaning of - a set of practices. It does not reduce practices to a text that cries out to be deciphered. Either move would amount to the cipher clerk positivism that Geertz sets out to avoid from the start. Only in a highly de-stabilized sense does Geertz speak of "reading a text" as a trope for observing and thickly describing social practices. One tries to "construct a reading of" (the original meaning of fictio) other people's constructions-perhaps momentary instances of actors, conduct, circumstances set within particular practical contexts (synchronically observed, but diachronically situated). These are "documents" in the sense of something that one "makes sense of"- "foreign, faded, full of ellipses, incoherencies, suspicious emendations, and tendentious commentaries" (Geertz 1973: 10). A "culture" is not a "text" to be read. It can be thought of as "an ensemble of texts, themselves ensembles, which the anthropologist strains to read over the shoulders of those to whom they properly belong" (1973: 452). How one renders the account can vary, and the act of rendering it cannot but alter the object to be rendered. ${ }^{19}$ In fact, the tasks of identifying, engaging, and

\footnotetext{
${ }^{19}$ William James helpfully elucidates the kind of impetus behind Geertz's "thick description": "There is nothing improbable in the supposition that analysis of the world may yield a number of formulae, all consistent with the facts. In physical science, different formulae may explain the phenomena equally well-the one-fluid and the two-fluid theories of electricity, for example. Why may it not be so with the world? Why may there not be different points of view for surveying it, within each of which all data harmonize, and which the observer may therefore either choose between or simply cumulate one upon another? A Beethoven string quartet is truly, as someone has said, a scraping of horses' tails on cats' bowels, and may be exhaustively described in such
} 
observing participate in the results of the observation made. Claims for normatively neutral "pure description" melt into air. ${ }^{20}$

For the forgoing reasons, it really is inadequate to speak of "culture" in the singular on a practice-theory reading of Geertz's account. And this observation reflects his view of a thickly descriptive ethnographic approach as much as it does the multiplicity and multi-facetedness of the object under investigation. Neither is stable and singular. Both remain in motion, under negotiation, contested-ensembles upon ensembles, fragmentary notes momentarily arranged rather than a snapshot of a static, stable social fact. Thick description describes and re-describes. The results have their value on the basis of a pragmatic criterion-how they push the discussion forward, widen possibilities of communication, open new ways of seeing and thinking, and draw previously unknown (and ostensibly excluded) voices and interlocutors into a widening, proliferating, and (ideally) increasingly self-critical and self-reflective range of conversations. Thus, Geertz writes:

What recommends [a particular account as opposed to another], or disrecommends them if they are ill-constructed, is the further figures that issue from them: their capacity to lead on to extended accounts which, intersecting other accounts of other matters, widen their implications and deepen their hold. We can always count on something else happening, another glancing experience, another half-witnessed event. What we can't count on is that we will have something useful to say about it when it does. (1995: 18-19)

The basic point of "thick description" is to interpretively discern and conceptually re-describe these socially instituted practices, and the norms implicit in those practices.

So far I have highlighted several features of a Wittgensteinian approach to practice theory by reading portions of Geertz's work with specific attention to the Wittgensteinian influences implicit in it. In the section that remains, I will explore what such a practice theory account

\footnotetext{
terms; but the application of this description in no way precludes the simultaneous applicability of an entirely different description" (James 1991: 513).

20 "What is known is seen to be a product in which the act of observation plays a necessary role. Knowing is seen to be a participant in what is finally known." These insights emerged early in scientific investigation with Werner Heisenberg's principle of indeterminacy (1926). John Dewey expanded upon what they implied for philosophical and social analysis in his Gifford Lectures of 1928, The Quest for Certainty (1988: 160-164). These insights are reflected in the Deweyan strands of Geertz's account of "culture and the evolution of mind" (1973: 55-83).
} 
might imply both for reading Geertz and, more broadly, for cultural theory in the study of religion.

\section{WHAT IS THE USE IN CALLING GEERTZ A PRACTICE THEORIST?}

What relevance do the preceding insights have for cultural theorists? I see three instructive implications of a Wittgensteinian approach to practice theory for cultural theorists, both inside and outside the study of religion. The first implication applies to critical reservations about employing Wittgenstein to the study of culture more broadly. The second responds to the concern that a Wittgensteinian approach terminates in "theoretical quietism" so afraid of positive philosophical assertion that it eschews assessment and criticism altogether. In conclusion, I hope to articulate what such an approach contributes to recent discussions in the scholarly study of religion.

First, one general reservation that cultural theorists will have about a Wittgensteinian approach to practice theory is that it so emphasizes discerning the "coherence" of practices, that it in fact presupposes an overly integrated and system-centered object of analysis. Such an approach, it will be said, imposes normative coherence and meaning when it claims simply to uncover these as already implicit in social practices. And indeed, one finds such charges leveled at Geertz, in part, due to the Wittgensteinian influences upon his work.

A practice theory reading should help side-step the claim that in identifying and describing "cultural practices" - and the "internal coherence" that discerning such practices presupposes-Geertz, in effect, solidifies "culture" into an overly integrated and rule-bound whole. On this reading, Geertz allegedly reduces practices to rule-following, thereby rendering "culture" a systematized or overly integrated substantial something (Asad 1993: 29). Now, clearly, various passages by Geertz invite such charges. Human action is "symbolic" for the fact that it "signifies," he writes. It "signifies" in virtue of participation in "patterns of life." Moreover, charges of excessive or forced coherence are exacerbated when Geertz is read as concerned primarily with semiotics. And indeed throughout much of his early writing. Geertz writes in ways that appear to elevate a notion of "symbol" to center stage. In fact, Geertz himself uses the word "semiotics" to describe the framework within which he made sense of the ways people interact. Similarly, the "ways of seeing" facilitated by "symbol systems" which he delineates as "religious," "common sensical," "ideological," "aesthetic" (among others) appear so clear and distinct as to be perhaps incommensurable in relation to one 
another. At times these features have created the impression that he viewed symbol systems as autonomous domains and symbol-users as self-sufficient creatures who confer significance by intentionally inscribing the symbols they use with meanings. However, Geertz's claim that meanings are "embodied in" symbols need not suggest that the latter "mysteriously imbue" the former, as though meaning was the animating ghost in the machine of the symbol.

In some of his more straightforward moments, Geertz makes clear that he takes meaning to be inseparable from all the embodied social practices of engaging in the actions, gestures, noises, and marks used to recognize and respond to activities of one's fellow human beings within the causally constraining environs in which all these are situated. Meaning is not "tacked onto" or "inscribed upon" actions or symbols. It is part and parcel to them, and occurs along with their uses in particular contexts and circumstances. Thought and feeling are both "inescapably dependent upon the utilization by individuals of socially available 'systems of significance,' cultural constructs embodied in language, custom, art, and technology - that is to say, symbols" (Geertz 1973: 18-19). But again, on a practice theory reading, the words "symbol" and "system" have no sacrosanct status. A practice theory reading views these terms as oriented by the other terms in the sentence-"utilization," "socially available," "cultural constructs," "embodied in language," and of course, Geertz's use of scare quotes to set off what he means by "systems of significance." "Symbol" becomes a trope for a component of social practice rather than the hinge for a theory of meaning. "Symbol systems" or "semiotics" become idioms for understanding Geertz insofar as they always and already presuppose a background of social practices. Meaning is a precipitate of use, and use presupposes practical "know how"-relative proficiency in navigating the proprieties in virtue of which social practices hang together.

Geertz's appeal to "systems" stands against the background of Wittgenstein's demonstration that "rule following"-and thus, any "rule" oriented account of social cohesion-is set against a background of social practices. Following a rule, Wittgenstein famously argued, presupposes knowing what such things as "rules" are-for instance, that they are bits of information that one "follows." On this account, discerning rules begins as practical discrimination-knowing how to identify and respond appropriately to this article or event that has the status of "a rule" within the social context in question. Rule following requires any number of other bits of know-how already in place prior to recognizing and applying the know-that formally articulated as a rule. Rather than referring to formally articulated sense-making structures, Geertz's 
invocation of the "public codes", according to which winking means something, simply designates the as yet un-thematized proprieties implicit in the practice of winking. These are proprieties that tacitly organize that practice. Accordingly, certain actions may be identified as coherent performances of that practice and certain practitioners as reliably able to perform that practice. These begin as practical discriminations between winking and blinking long before the publication of Rules for Winkers. The proprieties constitutive of practices may or may not be transcribed into explicit propositions as formally articulated rules through second-order reflection upon, and formal articulation of, those proprieties. The proprieties are implicit in the practice. Ryle called such background proprieties, or norms implicit in practices, "established codes." Geertz glosses Ryle's notion of "established codes" as "the informal logic of actual life." Both convey the idea that participation in a practice requires practically comprehending, getting a sufficient feel for, and some degree of adeptness or skill in navigating the socially instituted, normative relations that constitute social practices (Ryle 1949: 40-471). ${ }^{21}$

This strand of social practice thinking that extends from Ryle to Geertz is indebted to Wittgenstein's "regress-of-rules" argument"Thus is 'following a rule' Praxis" (Wittgenstein 2002: 201). Charles Taylor helpfully clarifies the central idea:

My embodied understanding ["a grasp on things which, although quite unarticulated, may allow us to formulate reasons and explanations when challenged"] doesn't only exist in me as an individual agent, but also as the coagent of common actions. This is the sense we can give to Wittgenstein's claim that obeying a rule is a practice. He means by this a 'social practice'." ... Earlier (198) he asks: "What has the expression of a rule-say a sign post-got to do with my actions? What sort of connection is there here?" His answer is "Well perhaps this one: I have been trained to react to this sign in a particular way, and now I do so react to it." ... But Wittgenstein moves right away to set aside this reading. His imaginary interlocutor says, "But that is only to give a causal connection," and the Wittgenstein voice in the text

\footnotetext{
${ }^{21}$ The deeply Wittgensteinian resonances are no mere coincidence. Geertz is following Ryle's The Concept of Mind at a near distance here. In terms of theoretical genealogy, the many points at which Geertz draws upon Ryle's work are also points at which he owes some of his deepest debt to Wittgenstein. Ryle worked closely with Wittgenstein from the time of their first encounter in 1929. For his comments about Wittgenstein's influence upon him, see Ryle's "Autobiographical" in Oscar P. Wood and George Pitcher, Ryle: A Collection of Critical Essays, pp. 5 and 11; see also Ray Monk's commentary on their time together in (1990) Wittgenstein: The Duty of Genius, pp. 275, 336-337 and 436; for Ryle's scholarly work on Wittgenstein, see Ryle (1951, 1957).
} 
answers: "On the contrary; I have further indicated that a person goes by a sign-post only insofar as there exists a regular use of sign-posts, a custom." This standing social use makes the connection, and it is not to be understood as merely causal one. The standing use gives my response its sense. It doesn't merely bring it on through a brute causal link. But the sense is embodied and not represented.... [T] he 'rule' lies essentially in the practice. The rule is what is animating the practice at any given time, and not some formulation behind it, inscribed in our thought or our brains or our genes, or whatever. That's why the rule is, at any given time, what the practice has made it. ${ }^{22}$

As Taylor points out here, the significance of the "rule" being generated by, and implicit in, the practice implies that one becomes a participant in these patterns through gradual initiation into the propriety-laden "know how" necessary to take part in the give-and-take of the respective complex of "intentions, expectations, circumstances, settings, and purposes that give actions their meanings." 23 Initiation into such "patterns of life" may look as inconspicuous as the child learning from her mother that "contracting your eyelids on purpose when there exists a congruity of acting in which so doing counts as a conspiratorial signal (winking)," and develops the requisite physical capability of closing and opening one eye, while keeping the other open. ${ }^{24}$ Again, the practical proprieties we identify reflexively as constitutive of practices do not constitute a logic prior to being re-described in the language of logic. Participants in social practices are not rule-makers and followers first who then apply in practice the rules that they antecedently invented or studied. Such an approach would resolve, like Scholasticus, not to set foot in water before having learned how to swim (Inwood 1989: 188). ${ }^{25}$

Geertz cautioned his readers against mistaking the occasionally positivist tones of his terminology for the irreducibly interpretive affair of thick description. "[S]orting out the structures of signification-what

\footnotetext{
22 Taylor deploys this account of "following a rule," in part, to explicate Wittgenstein's relation to Pierre Bourdieu's account of habitus (1999: 37-38, 42).

${ }^{23}$ Stephen Greenblatt paraphrasing Ryle, Collected Papers, Vol. 2, 465-496 in his essay, (1998), "A Touch of the Real."

${ }^{24}$ Hubert Dreyfus distills a similar concept of social practice from Martin Heidegger's Being and Time: "Practices are social skills [by which] I mean that there is a convergence of skills, that is, everyone does things roughly the same way .... People just naturally conform to what everyone does. Social practices are what one does. If you thematize that, you get the idea of norms, although the people who are acting them out do not think of their practices as norms." See Dreyfus (1992: 27) "Reflections on the Workshop on 'the Self." For a sense of the ways that Wittgenstein alleviates the abstraction of Heidegger's account, see Dreyfus and Rabinow (1999).

25 Taylor provides an account of how Hegel's thought orients the landscape of social practice thinkers, see Taylor (1979) Hegel and Modern Society, pp. 135-169.
} 
Ryle called established codes, [is] a somewhat misleading expression, for it makes the enterprise sound too much like that of the cipher clerk when it is much more like that of the literary critic..." (1973: 9). And elsewhere, "[W] hat we call our data are really our own constructions of other people's constructions of what they and their compatriots are up to-[and this fact] is obscured because most of what we need to comprehend a particular event, ritual, custom, idea, or whatever is insinuated as background information before the thing itself is directly examined" (9). "Thick description," then, is not a matter of simply abstracting from the currency of exchange of daily living in order to peer in and articulate the single logic therein. Thickly describing "cultural systems" is better thought of as "getting a feel" for what is going on, rather than consulting a rule book or detecting a deep structure. He expands the point:

[O]ne cannot run symbolic forms through some sort of cultural assay to discover their harmony content, their stability ratio, or their index of incongruity. One can only look and see if the forms in question are in fact coexisting, changing, or interfering with one another in some way or other, which is like tasting sugar to see if it is sweet or dropping a glass to see if it is brittle, not like investigating the chemical composition of sugar or the physical structure of glass. (1973: 404-405)

Only after the fact does one sketch the subject matter under some description, rather than purporting to reduce it once and for all to an essence or meaning antecedently settled in virtue of a general "theory of meaning" or phenomenological apparatus. Again, "meaning" is not a magical wand that actors use to "inscribe" things with significance, nor is it an essential something that cultural phenomena bear as a common object of analysis. It is something that varies on a case-by-case basis and requires careful attention to context specifics. "[I] do not think meanings are out there to theorize about," Geertz clarified in an interview of recent years. "One tries to look at behavior, what people say, and make sense of it-that is my theoretical approach to meaning" (Micheelsen 2002: 6).

Of course, even if my reading sounds plausible up to this point, the question of "theoretical quietism" remains to be considered. This brings us to the second implication we can draw from a Wittgensteinian approach to practice theory. Does the aim to identify, describe, and re-describe practices and practical contexts result in an approach that "simply puts everything before us, and neither explains nor deduces anything" and finally "leaves everything as it is"? Interestingly, the 
critical and even transformative potential of a practice theory framework informed by Wittgenstein's work derives from the notion that social practices, while not simply "rule bound" or determined by "deep structures," are nonetheless organized by normative constraints. The notions of constraint and innovation may initially seem to be at odds. Moreover, positing their simultaneity as a means of critical leverage and a condition of the possibility of transformative analysis may seem oddly counter-intuitive. I will attempt to explain why they are not.

Becoming increasingly adept at the application of the proprieties constitutive of some practice-and the physiological capabilities to execute the actions correctly-permits the possibility of innovative performance of the practices in question, and even criticism of poorly, inaccurately, or inappropriately executed instances of the practice. For present purposes, winking presents a concrete instance of a "human action ... made by 'structure,' [that] at the same time always makes and potentially unmakes it" (Ortner 1996: 2). The bare action of closing and opening one eye-lid has the potential to become-in light of particular context and innovative application of the organizing proprieties-rehearsal, play, gesture of friendship, flirtation, parody, conspiracy, or some other signal. Because practices are candidates for novel application and performance, whatever "minimal coherence" that thick description attempts to make sense of, such coherence is in flux-subject to change, development, transformation, innovation, criticism, imitation, parody, etc. Now, clearly, Geertz rarely (if ever) addresses questions of power, domination, and resistance. However, there seems to be no reason why an account that understands agency as enabled by practical normative constraints and congruities could not direct its attention to how those constraints might be used for purposes of manipulation, innovation, and improvisation. On the Wittgensteinian account I have worked to articulate above, any such activity is a prime candidate for having its organizing proprieties explicated and criticized. ${ }^{26}$ This is a far cry from the notion that philosophy (or analysis, thick description) "simply puts everything before us, and neither explains nor deduces anything," and in fact, "leaves everything as it is" (Malcolm 1954: 550; Wittgenstein 2002: sec 126, 124). Re-framed within this social-practice framework means that, far from a search for a single "logic implicit in practice," thick descriptions are to be context sensitive, flexible, underdetermined in their terms of description. It becomes

\footnotetext{
${ }^{26}$ For readings of Wittgenstein that emphasize the centrality of social practice for the purposes of critical social and political analysis in contrast to rationalist and hermeneutical approaches, see Tully (1986) and Mouffe (2000). I make a sustained case that social practice analysis can facilitateand enhance-power analysis aimed at issues of race and gender in Springs (2007 and forthcoming).
} 
an approach to reflecting critically upon social practices through discerning, explicating, describing, and re-describing "what the devil is going on." Asad and Ortner are correct to say that attending to social practices is a crucial (if not necessary) step in uncovering and interrogating operations of power in a range of productive and dominating manifestations (Asad 1993: 43; Ortner 1999: 138-139). However, to assert that Geertz not only does not, but cannot accommodate such critical attention to practice is to incorrectly position his project.

The third implication of a Wittgensteinian approach to practice theory is more immediately pertinent to the study of religion. Insofar as it is accurate to read Geertz as reflecting a Wittgensteinian account of practice, then it is incorrect to charge him with privileging "thought, structure and the synchronic" in his analysis of religious practices (Bell 1992: 77). Yet such charges are fairly common. Asad, for instance, claims that "Geertz's treatment of religious belief, which lies at the core of his conception of religion, is a modern, privatized Christian one because and to the extent that it emphasizes the priority of belief as a state of mind rather than as constituting activity in the world" (Asad 1993: 47). Inspection at the level of detail, however, indicates that neither inner intention nor believing is primarily a mental act for Geertz. In fact, "mind" itself is neither "mental" nor "interior" in the "modern, privatized" sense of those terms. "Human thought is consummately social," Geertz writes, "social in its origins, social in its functions, social in its forms, social in its applications. At base, thinking is a public activity-its natural habitat is the houseyard, the marketplace, and the town square" (1973: 360). Individual "subjectivity" and "experience" appear on the scene only after long processes of acculturation and practice. ${ }^{27}$ The same can be said for things like intention and belief. On a social-practice reading, these are most basically social and intrinsically embodied.

Highlighting this dimension of Geertz's work draws him into the orbit of recent work on belief and ritual by cultural theorists in religion. In a practice theory framework, for instance, "believing" becomes a historically situated and socially embodied "habit of action" that can take on the form of a propositionally articulated and cognitively maintained representation of reality only derivatively. ${ }^{28}$ "Believing" begins as

\footnotetext{
27 "'Mind' is a term denoting a class of skills, propensities, capacities, tendencies, habits; it refers in Dewey's phrase to an 'active and eager background which lies in what and engages whatever comes its way”' (Geertz 1973: 58).

${ }^{28}$ Kevin Schilbrack has made the case (successfully in my judgment) that Geertz's use of Wittgenstein counters Asad's charge of "belief as a state of mind" (2005: esp. 438-440). Catherine Bell offers a compatible treatment of "believing" (Bell 2002: 100-116), and Nick Crossley provides a treatment of the concept of ritual along these lines (Crossley 2004: 31-51). Of course, my present
} 
"dispositions" (broadly construed). Dispositions are not subjective feelings (Geertz quite explicitly rejects the forms of Cartesianism that would identify dispositions with "mental traits" or "psychological forces"), but rather "tendencies, capacities, propensities, skills, habits, liabilities, pronesses" which prompt various actions and responses with the surrounding environment and circumstances (1973: 95-96). Of course, such dispositions do not form out of nothing, nor are they static and impervious to change and critical reflection. Yet they presuppose (however tacitly) some sense of what the world is like and how things around the actor "simply are" - a sense of the world into which one finds oneself thrown, socialized, and which one finds oneself trusting. Similarly, for Wittgenstein, what "I believe" is most basically embodied in the manner in and through which I interact with the world around me and of which I am an inextricably interrelated part. This is often (perhaps usually) without my reflecting on-perhaps without being able to justify or to bring it to the level of explicit articulation-what it is precisely that "I believe." So understood, "believing" is better described as a sensibility of trust that is required for getting around in the world, or any form of comportment beyond the self-parodying pyrrhonistic skepticism frequently tilted at by professional philosophers and theorists. Of course, one need be a skeptic to become the kind of fixated theoretician against which Wittgenstein inveighed.

\section{CONCLUSION}

I am sitting with a philosopher in the garden; he says again and again "I know that that's a tree", pointing to a tree that is near us. Someone else arrives and hears this, and I tell him: “This fellow isn't insane. We are only doing philosophy." - Ludwig Wittgenstein (1969)

I hope to have offered incentive for re-considering Wittgenstein's potential contribution to cultural analysis and criticism in ways relevant to both cultural theory and the study of religion. I attempted to do this by demonstrating how certain of Wittgenstein's influences in this regard can be illustrated by a practice theory reading of Geertz's work. I argued that such an approach proposes interpretive analysis that can occur across a range of possible re-descriptions. This does not implicate itself in a static and over-determined conception of "culture," nor need

task of re-reading Geertz in a practice theory frame is but an initial (though necessary) step toward putting these resources in conversation in the study of religion. 
it terminate in a theoretical or critical quietism. Neither, moreover, does it relieve the necessity of making all things considered, object-directed judgments about better and worse, correct and incorrect analyses. At the same time, however, this approach strives to be intentionally nonreductive (even though readings considered "reductive" are ostensibly as viable as potential contenders in the investigative exchange as any others). Here a reading's viability is "ostensive"-at least initiallybecause it is to be judged on the concrete content of its claims relative to the nature of the case and the interests at hand, rather than ruled out (or in) on an a priori basis (for instance, in virtue of its motivating commitments or methodological presuppositions). Of course, while it avoids theoretical quietism, this approach remains cautious of theoretical fixations as well. It examines the source of our fascination with marking out our fields of investigation in hard-and-fast dichotomies like "first-" vs. "second-order" levels of discourse, "insider" vs. "outsider" status, and "critic" vs. "caretaker." The point is not simply to demystify our categories of analysis only to remake them new and improved. The point is to cultivate sensibilities and skills of observation, interpretation, translation, criticism, and assessment precisely because we cannot take for granted pervasive underlying agreement about even the most basic field-demarcating assumptions.

Abu-Lughod, Lila 1991

Asad, Talal 1993

Bell, Catherine 1992

2002

Bernstein, Richard 1983

\section{REFERENCES}

"Writing against Culture." In Recapturing Anthropology: Working in the Present. Ed. by Richard G. Fox. Santa Fe: SAR Press.

"Construction of Religion as an Anthropological Category." Genealogies of Religion. Baltimore, MD: Johns Hopkins University Press.

Ritual Theory Ritual Practice. Oxford: Oxford University Press.

"The Chinese Believe in Spirits': Belief and Believing in the Study of Religion." In Radical Interpretation in Religion. Ed. by Nancy Frankenberry. Cambridge: Cambridge University Press. 100-116.

Beyond Objectivism and Relativism. Philadelphia: University of Pennsylvania Press. 
Bowlin, John and

Peter Stromberg 1997

Cioffi, Frank 1998

Clack, Brian R. 2001

Clifford, James and G. E. Marcus, eds. 1986

Crossley, Nick 2004

Davaney, Sheila Greeve and Warren Frisina, eds. 2006

de Certeau, Michel 1984

Dewey, John 1988

Dirks, Nicholas B., ed. 1998

Dirks, Nicholas, Geoff Eley and Sherry Ortner, eds. 1994

Davidson, Donald 1973

Dreyfus, Hubert 1992
"Representation and Reality in the Study of Culture," American Anthropologist 99/1 (March): 123-134.

Wittgenstein on Freud and Frazer. Cambridge: Cambridge University Press.

Wittgenstein, Frazer and Religion. New York: St. Martin's Press.

Writing Culture: The Poetics and Politics of Ethnography. Berkeley, CA: University of California Press.

"Ritual, Body, Technique, and (inter) Subjectivity." In Thinking Through Rituals. Ed. by Kevin Schilbrack. New York: Routledge.

Pragmatic Century: Conversations with Richard J. Bernstein. Albany, NY: State University of New York Press.

The Practice of Everyday Life. Berkeley: University of California Press.

The Quest for Certainty. Carbondale: Southern Illinois University Press.

Near Ruins: Cultural Theory at the End of the Century. Minneapolis: University of Minnesota Press.

Culture/Power/History. Princeton: Princeton University Press.

"On the Very Idea of a Conceptual Scheme." Proceedings and Addresses of the American Philosophical Association 47. Reprinted in Davidson, Inquiries into Truth and Interpretation. 183-198. Oxford: Oxford University Press, 2001.

"Reflections on the Workshop on 'the Self" Anthropology and Humanism Quarterly 16/1: 27-31.

"Can There Be a Science of the Existential Structure and Social Meaning?" In Bourdieu: 
Dreyfus, Hubert and Paul Rabinow 1999

Edwards, James C. 1983

1990 The Authority of Language: Heidegger, Wittgenstein, and the threat of Philosophical Nihilism. Tampa, FL: University of South Florida Press.

Evans-Pritchard, E. Witchcraft, Oracles and Magic Among the 1937 Azande. Oxford: Clarendon Press.

Fowl, Stephen. "Could Horace Talk to the Hebrews? 1991 Translatability and Moral Disagreement in MacIntyre and Stout." Journal of Religious Ethics 19:1-20.

Fox, Richard G. and Barbara J. King, eds. 2002

Giddens, Anthony 1979

Geertz, Clifford 1971

1973 The Interpretation of Cultures. New York: Basic.

1983 "From the Native's Point of View: On the Nature of Anthropological Understanding." Local Knowledge. New York: Basic.

1984 "Anti Anti-Relativism." The American Anthropologist 82/2:263-278.

1995 After the Fact. Cambridge: Harvard University Press.

2000 Available Light. Princeton: Princeton University Press. 
Greenblatt, Stephen 1998

Gupta, Akhil and James Ferguson 1992

Harvey, Van A. 2007

Herbert, Christopher 1991

Hollis, Martin and Steven Lukes eds. 1982

Hopkins, Jim 1998

Hoy, David 1996

Incandela, Joseph 1985

Inwood, Michael, ed. 1989

James, William 1991

Lovibond, Sabina 1983

Lukes, Stephen 1982
"A Touch of the Real." The Fate of Culture: Geertz and Beyond. Ed. by Sherry Ortner. Berkeley: University of California Press.

Beyond 'Culture': Space, Identity, and the Politics of Difference," Cultural Anthropology 7/1 (February): 6-23.

"Wittgensteinian Fideism?-By Kai Nielsen and D. Z. Phillips." Philosophical Investigations 30/3:319-323.

Culture and Anomie. Chicago: University of Chicago Press.

Rationality and Relativism. Cambridge: MIT Press.

"Wittgenstein, Davidson, and Radical Interpretation." In The Philosophy of Donald Davidson. Ed. by Lewis Hahn, 255-285. Peru, IL: Open Court.

"Post-Cartesian Interpretation." in The Philosophy of Hans-Georg Gadamer. Ed. by Lewis Edwin Hahn, 111-128. Peru, IL: Open Court Publishing.

“The Appropriation of Wittgenstein's Work By Philosophers of Religion: Towards a Re-Evaluation and an End." Religious Studies 21:457-474.

Hegel Selections. New York: MacMillan.

"The Sentiment of Rationality." In Writings: 1878-1899. Ed. by Gerald Myers, 504-539. New York: The Library of America.

Realism and Imagination in Ethics. Minneapolis: University of Minnesota Press.

"Relativism in its Place." In Rationality and Relativism. Ed. by Martin Hollis and Steven Lukes, 261-305. Cambridge: MIT Press. 
MacIntyre, Alasdair "Is Understanding Religion Compatible with 1970a Believing?” In Rationality. Ed. by Bryan Wilson, 62-77. Oxford: Basil Blackwell.

1986 "Relativism, Power, and Philosophy." In After Philosophy. Ed. by Kenneth Baynes, James Bohman and Thomas McCarthy, 385-411. Cambridge: MIT Press.

Malcolm, Norman "Wittgenstein's Philosophical Investigations."

1954 The Philosophical Review 63/4 (October): 530-559.

1977 "The Groundlessness of Belief." In Reason and Religion. Ed. by Stuart C Brown, 92-103. New York: Cornell University Press.

1995 Wittgenstein: A Religious Point of View? Ithaca, NY: Cornell University Press.

McCutcheon, Russell "On the Limits of the Humanistic Study of 2006 Religion." Journal of the American Academy of Religion 74/3 (September): 720-750.

McCutcheon, Russell, ed. The Insider/Outsider Problem in the Study of 1999 Religion. New York: Cassell.

McDowell, John Mind and World. Cambridge: Harvard 1996 University Press.

Micheelsen, Arun “I Don't Do Systems': An Interview with 2002 Clifford Geertz." Method and Theory in the Study of Religion 14: 2-20.

Monk, Ray Wittgenstein: The Duty of Genius. New York: 1990 Penguin.

Mouffe, Chantal "Wittgenstein, Political Theory \& Democracy." 2000 In The Democratic Paradox, 60-79. New York: Verso.

Nielsen, Kai “Wittgensteinian Fideism." Philosophy 42/161 1967 (July): 191-209.

Nielsen, Kai and Witggensteinian Fideism? London: SCM Press.

D. Z. Phillips 
Ortner, Sherry

1995

1996

1999

2006

Orville, Lee

1999

Pals, Daniel

1996

Pecora, Vincent

1989

Phillips, D. Z.

1971

1976

2001

Placher, William

1989

Proudfoot, Wayne 1985

Putnam, Hilary 1992
"Resistance and the Problem of Ethnographic Refusal." Comparative Studies in Society and History 37/1 (January): 173-193.

Making Gender: The Politics and Erotics of Culture. Boston, MA: Beacon Press.

"Thick Resistance: Death and Agency in Himalayan Mountaineering." In The Fate of Culture: Geertz and Beyond. Ed. by Sherry Ortner. California: California University Press.

Anthropology and Social Theory: Culture, Power and the Acting Subject. Durham, NC: Duke University Press.

"Observations on Anthropological Thinking About the Culture Concept: Clifford Geertz and Pierre Bourdieu." In Pierre Bourdieu. Ed. by D. Robbins. London: Sage Publications.

Seven Theories of Religion. Oxford: Oxford University Press.

"The Limits of Local Knowledge." In The New Historicism. Ed. by H. Aram Veeser, 243-276. New York: Routledge.

"Religious Beliefs and Language Games." In Philosophy of Religion, 121-142 Ed. by Basil Mitchel. Oxford: Oxford University Press.

Religion Without Explanation. Oxford: Basil Blackwell.

Religion and the Hermeneutics of Contemplation. Cambridge: Cambridge University Press.

Unapologetic Theology. Louisville, KY: Westminster/John Knox.

Religious Experience. Berkeley: University of California Press.

Renewing Philosophy. Cambridge: Harvard University Press. 


$\begin{aligned} \text { Ramberg, Bjorn } & \begin{array}{l}\text { Donald Davidson's Philosophy of Language. } \\ \text { Oxford: Wiley-Blackwell. }\end{array} \\ \text { Rorty, Richard } & \begin{array}{l}\text { Philosophy and the Mirror of Nature. Princeton: } \\ 1979\end{array} \\ 1992 & \begin{array}{l}\text { Princeton University Press. } \\ \text { "Wittgenstein, Heidegger and the Reification of } \\ \text { Language." In The Cambridge Companion to } \\ \text { Heidegger, 337-357. Ed. by Charles Guigon. } \\ \text { Cambridge: Cambridge University Press. }\end{array}\end{aligned}$

Roseberry, William Anthropologies and Histories. New Jersey: 1989 Rutgers University Press.

Rosenzweig, Franz Franz Rosenzweig: His Life and Thought. Ed. by 1998 Nahum N. Glatzer. Indianapolis, IN: Hackett Publishing Company.

Ryle, Gilbert The Concept of Mind. Chicago: University of 1949 Chicago Press.

1951 “Ludwig Wittgenstein.” Analysis XII: 1-9.

1957 "Review of Ludwig Wittgenstein: Remarks on the Foundations of Mathematics." Scientific American CXVII: 251-259.

Sahlins, Marshall Historical Metaphors and Mythical Realities. 1981

Schilbrack, Kevin Ann Arbor: University of Michigan Press.

2005

"Religion, Models of, and Reality: Are We Through with Geertz?" Journal of the American Academy of Religion 73/2: 429-452.

Smith, Wilfred Cantwell

"The Comparative Study of Religion: Wither 1959 and Why?" In The History of Religions: Essays in Methodology. Ed. by Mircea Eliade and Joseph Kitagawa, 31-58. Chicago: Chicago University Press.

Soames, Scott Philosophical Analysis in the Twentieth 2002 Century, Vol. 2. Princeton: Princeton University Press.

Springs, Jason "The Priority of Democracy to Social Theory." 2007 Contemporary Pragmatism 4/1: 47-71. 
Forthcoming

Steedly, Mary Margaret 1996

Stiver, Dan

1996

Stout, Jeffrey

1981

2001

Tambiah, Stanley

1989

Taylor, Charles

1979

1982

1999

Toulmin, Stephen 1990

Tully, James

1986

Wilson, Bryan, ed. 1970

Winch, Peter 1958

$1970 \mathrm{a}$
“'Dismantling the Master's House': Freedom as Ethical Practice in Robert Brandom and Michel Foucault." Journal of Religious Ethics. Oxford: Blackwell.

"What is Culture? Does it Matter?" In Field Work. Ed. by Marjorie Garber, Paul B. Franklin and Rebecca L. Walkowitz. New York: Routledge.

The Philosophy of Religious Language. Oxford: Blackwell.

The Flight from Authority. Notre Dame, IN: Notre Dame University Press.

Ethics After Babel. Princeton: Princeton University Press.

Magic, Science, and the Scope of Rationality. Cambridge: Cambridge University Press.

Hegel and Modern Society. Cambridge: Cambridge University Press.

"Rationality." In Rationality and Relativism. Ed. by Martin Hollis and Steven Lukes, 87-105. Cambridge, MA: MIT.

"To Follow a Rule." In Bourdieu: A Critical Reader. Ed. by Richard Shusterman, 29-44. Oxford: Blackwell.

Cosmopolis. Chicago: University of Chicago Press.

"Wittgenstein and Political Philosophy." Political Theory 17/2 (May): 172-204.

Rationality. Oxford: Blackwell.

The Idea of a Social Science and Its Relation to Philosophy. Atlantic Highlands, NJ: Humanities Press International, Inc.

"The Idea of a Social Science." In Rationality. Ed. by Bryan Wilson, 1-17. Oxford: Basil Blackwell. 
1970b "Understanding a Primitive Society." Rationality. Ed. by Bryan Wilson, 78-111. Oxford: Basil Blackwell.

1987 "Language, Belief and Relativism." Trying to Make Sense. Oxford: Blackwell.

Wittgenstein, Ludwig In On Certainty. Ed. by G. E. M. Anscombe and 1969 G. H. von Wright, 61e. Oxford: Basil Blackwell.

1993 "Remarks on Frazer's Golden Bough." Philosophical Occasions, 1912-1951. Ed. by James Carl Klagge and Alfred Nordmann, 118-155. Indianapolis, IN: Hackett.

2002 Philosophical Investigations. Oxford: Blackwell. 